\title{
CRIME E CASTIGO NOS ESTADOS UNIDOS: DE NIXON A CLINTON ${ }^{1}$
}

\author{
Loïc Wacquant \\ University of California-Berkeley \\ Centre de Sociologie Européenne du Collège de France
}

\begin{abstract}
RESUMO
Este artigo analisa o crescimento exponencial do número de detentos ocorrido nos Estados Unidos a partir de meados dos anos 70. Procura mostrar que esse crescimento não corresponde a um aumento da criminalidade, mas à conjugação de três séries causais, quais sejam: o declínio do "ideal de reabilitação" dos prisioneiros, a instrumentalização do medo da violência pelos políticos e pela mídia e a função de mecanismo de controle racial assumido pelo sistema penal americano. Em suma, a hiperflação carcerária revela a contraface do enfraquecimento do Estado de Bem-Estar Social e a sua substituição por um Estado penal.
\end{abstract}

PALAVRAS-CHAVE: Estado penal; Estado de bem-estar social; sistema penitenciário; punição; criminalidade; penalogia; hiperinflação carcerária.

\section{INTRODUÇÃO}

Em 1967, enquanto a Guerra do Vietnã e as revoltas raciais sacudiam os Estados Unidos, o Presidente Johnson recebia de um grupo de especialistas um inventário sobre o sistema judiciário e penitenciário americano. A "Comissão sobre a Administração da Lei e da Justiça” revelava então que a população detida nas prisões federais e nas casas de detenção estaduais diminuía lentamente, em torno de $1 \%$ ao ano (PRESIDENT'S COMMISSION, 1967). Naquele ano, os estabelecimentos penitenciários dos Estados Unidos confinavam 426000 pessoas, número que deveria aumentar para $523000 \mathrm{em} \mathrm{1975,} \mathrm{sob} \mathrm{o} \mathrm{efeito} \mathrm{do}$ crescimento demográfico nacional. Nem a superlotação das prisões, nem a inflação dos efetivos carcerários estavam na ordem do dia. $\mathrm{O}$

1 Crime et châtiment en A merique de $\mathrm{N}$ ix on a Clinton. D epartment of Sociology, University of California-Berkeley, digit. November 1997. Tradução: Vilma Aguiar. Revisão técnica: Adriano Nervo Codato e Pedro Rodolfo Bodê de Moraes. N. do T.: Aqui, a palavra "châtiment" foi traduzida por "castigo" para manter a alusão, contida na versão francesa, ao romance de F. D ostoievsky. No restante do texto, 0 termo foi traduzido por "punição". Este artigo foi originalmente publicado em: A rchives de politique criminelle, n. 20, p. 123-138, mai 1998. Traduzido sob permissão do autor. governo federal se propunha, aliás, a acelerar a deflação destes últimos através de um uso ampliado da liberdade vigiada e da generalização de penas alternativas.

Seis anos mais tarde, Richard Nixon recebia por sua vez um relatório sobre a evolução do sistema carcerário norte-americano. A National Advisory Commission on Criminal Justice Standards and Goals notava, na verdade, que a população encarcerada cessara de refluir. Mas nem por isso deixara de recomendar uma moratória de dez anos na construção de prisões, assim como o fechamento progressivo dos estabelecimentos para jovens detentos. Isso porque estava comprovado que "a penitenciária, a casa de correção e a prisão nada têm feito além de acumular fracassos vexatórios. São incontestes as provas que demonstram que essas instituições geram mais criminalidade que a previnem" (NATIONAL ADVISORY COMMISSION, 1973, p. 597).

$\mathrm{Na}$ mesma época, Alfred Blumstein e seus colaboradores propunham sua teoria "homeostática" do nível de encarceramento nas sociedades modernas. Segundo o célebre criminalista, cada sociedade apresenta não um nível "normal" de criminalidade, como queria Émile Durkheim, mas um nível constante de punição, que se traduz por uma taxa estável de encarceramento (BLUMSTEIN 
\& COHEN, 1973). Quando essa taxa se afasta de seu limite natural, diversos mecanismos estabilizadores entram em ação: a polícia, os promotores, os tribunais e os juízes que aplicam as penas ajustam suas práticas num sentido permissivo ou restritivo, a fim de redesenhar o perímetro dos comportamentos suscetíveis de serem punidos e, por conseguinte, reduzir ou aumentar o volume das pessoas atrás das grades (como aliás o provam as baixas oscilações da população penitenciária reveladas pelas estatísticas norte-americanas, canadenses e norueguesas desde a grande crise, de fato desde o fim do século XIX) (cf. BLUMSTEIN, COHEN \& NAGIN, 1976).

Não há sequer um dentre os historiadores revisionistas da instituição penal, de David Rothman (1971) a Michael Ignatieff (1978), passando por Michel Foucault (1975), que não tenha visto no encarceramento uma prática destinada a ocupar um lugar secundário no arsenal contemporâneo dos instrumentos de punição. Assim, para Foucault, se a "técnica penitenciária" desempenha um papel-motor no advento da "sociedade disciplinar", é porque ela se difunde através do "corpo social inteiro" e favorece a transição de uma "justiça inquisitória" a uma "justiça examinatória". A prisão propriamente dita é apenas uma ilha dentre outras no vasto "arquipélago carcerário" da modernidade, que articula a família, a escola, o convento, o hospital e a fábrica e do qual participam as Ciências Humanas: "Dentre todos esses dispositivos de normalização que se densificam, a especificidade da prisão e seu papel de articulação perdem sua razão de ser" (FOUCAULT, 1975, p. 305-313).
Sublinhando essa tendência à dispersão do controle social exercido pelo Estado, a sociologia "radical" da prisão apressava-se em denunciar no mesmo impulso os efeitos perversos alcançados pelas medidas de "desencarceramento" (SCULL, 1977; COHEN, 1979). Enfim, um consenso formou-se ao longo da década de setenta entre políticos, cientistas e críticos, segundo o qual a prisão não estava destinada a um futuro radioso ${ }^{2}$.

\section{O AUMENTO DA POLÍTICA DE ENCARCE- RAMENTO}

Nada era menos verdadeiro: a partir de 1973, a evolução penal americana iria bruscamente se inverter e a população encarcerada conheceria um crescimento exponencial sem precedentes na história das sociedades democráticas. Logo depois da revolta na Attica, momento de orgulho de contestação da prisão, os Estados Unidos apresentavam uma taxa de encarceramento inferior a 100 detentos por 100000 habitantes - próxima, portanto, daquela da França de hoje. Treze anos mais tarde, esta taxa havia triplicado para atingir 313 , antes de dobrar novamente na década seguinte e de atingir os 600 por 100000 em 1995, ou seja, duas vezes mais que a África do Sul sob o regime do apartheid e seis a doze vezes mais que os países da União Européia. Durante a última década, os Estados Unidos reuniram perto de um milhão de detentos, ao ritmo infernal de 1618 prisioneiros suplementares por semana (cf. Tabela 1). No dia $1^{\circ}$ de janeiro de 1997 , a população das prisões municipais, estaduais e federais chegava a 1731 500 pessoas $^{3}$.

Tabela 1 - Crescimento da população carcerária americana, 1975-1995

\begin{tabular}{lccccc}
\hline & $\mathbf{1 9 7 5}$ & $\mathbf{1 9 8 0}$ & $\mathbf{1 9 8 5}$ & $\mathbf{1 9 9 0}$ & $\mathbf{1 9 9 5}$ \\
\hline Penitenciárias estaduais e federais & 240593 & 315974 & 480568 & 739980 & 1078357 \\
Casas de detenção (cidades e condados) & 138800 & 182288 & 256615 & 405320 & 507044 \\
Total de presos & 379393 & 498262 & 737183 & 1145300 & 1585401 \\
Crescimento a cada 5 anos & - & $31,3 \%$ & $47,9 \%$ & $55,4 \%$ & $38,4 \%$ \\
Crescimento acumulado & 100 & 131 & 194 & 302 & 418 \\
$\begin{array}{l}\text { Taxa de encarceramento } \\
\text { (por 100 000 habitantes) }\end{array}$ & 176 & 220 & 310 & 460 & 603
\end{tabular}

Fonte: BUREAU OF JUSTICE STATISTICS, Correctional Population in United States, 1995. Washington : U. S. Government Printing Office, 1996; BUREAU OF JUSTICE STATISTICS, Jail and Jail Inmates 1993-1994, Washington: U. S. Government Printing Office, 1995.

2 Zimring \& Hawkins (1991) mostram, em uma obra de exemplar rigor conceitual e empírico, como o nível de encarceramento foi ignorado pelo conjunto das analistas da prisão, de sociólogos a criminalistas, passando por historiadores, economistas e pelos estatísticos encarregados da pre- visão da administração penitenciária. Eles também recenseiam as causas da cegueira específica de cada modo de análise antes de esboçar uma "economia política do encarceramento".

3 Existem três tipos de estabelecimentos carcerários nos 
Poderíamos pensar que após quinze anos de um crescimento tão desenfreado, as prisões chegariam à saturação e que certos mecanismos homeostáticos postulados por Blumstein seriam desencadeados. De fato, as penitenciárias federais operam hoje com $146 \%$ de sua capacidade e os estabelecimentos estaduais com $131 \%$, mesmo quando se considera que seu número passou de 400 estabelecimentos em 1965 para 1450 em 1995 (dos quais 309 de "alta segurança"). Desde 1992, 40 dos 50 membros da União e o distrito de Colúmbia, no perímetro da capital Washington, foram notificados pelos tribunais a fim de remediar a superlotação e a degradação das condições de detenção, sob pena de pesadas multas e da proibição de encarcerar, a ponto que inúmeros dentre eles tiveram de soltar imediatamente milhares de prisioneiros para desafogar seus estabelecimentos e que mais de 50000 criminosos condenados a penas superiores a um ano encontram-se, hoje, presos nos cárceres municipais por falta de lugar nas penitenciárias estaduais.

Mas a bulimia carcerária americana não diminuiu em função disso: no fim do ano de 1995, apenas, 107300 pessoas a mais se encontravam atrás das grades, ou seja, 2064 detentos a mais por semana (BUREAU OF JUSTICE STATISTICS, 1996). Oito estados viram sua população encarcerada aumentar mais de 50\% entre 1990 e 1995: Arizona, Wisconsin, Geórgia, Minnesota, Mississipi, Virgínia, Carolina do Norte e o Texas - que detém o recorde nacional, duplicando o número de detentos em 5 anos. Em 1993, seis estados contavam cada um com mais prisioneiros que a França (ver Tabela 2). Apenas a Califórnia, com 31 milhões de habitantes, detinha quase tanto quanto os onze países continentais da Comunidade Européia juntos.

Tabela 2 - Estados líderes da inflação carcerária nos Estados Unidos em 1993

\begin{tabular}{|c|c|c|c|c|}
\hline & \multicolumn{3}{|c|}{ População encarcerada } & \multirow{2}{*}{$\begin{array}{c}\text { Taxa de } \\
\text { encarceramento } \\
\text { (por } 100 \text { 000) }\end{array}$} \\
\hline & $\begin{array}{c}\text { Prisões estaduais } \\
\text { e federais }\end{array}$ & Prisões municipais & Total encarcerado & \\
\hline Califórnia & 119951 & 69298 & 189249 & 607 \\
\hline Texas & 71103 & 55395 & 126498 & 700 \\
\hline Nova lorque & 64569 & 29809 & 94378 & 519 \\
\hline Florida & 53048 & 34183 & 87231 & 636 \\
\hline Ohio & 40641 & 11695 & 52336 & 473 \\
\hline Michigan & 39529 & 12479 & 52008 & 550 \\
\hline França & - & - & 51457 & 84 \\
\hline Geórgia & 27783 & 22663 & 50446 & 730 \\
\hline Ilinóis & 34495 & 14549 & 49044 & 420 \\
\hline Pensilvânia & 26050 & 19231 & 45281 & 376 \\
\hline Estados Unidos & 948881 & 459804 & 1408685 & 546 \\
\hline
\end{tabular}

Fonte: dados das prisões municipais: BUREAU OF JUSTICE STATISTICS, Jail and Jail Inmates 1993-1994. Washington : U. S. Government Printing Office, 1995; dados das prisoes estaduais e federais: BUREAU OF JUSTICE STATISTICS, Prisioners in 1993 Washington : U. S. Government Printing Office, 1994; dados da população dos estados: estimativas do Bureau of Census (homepages na Web).

$\overline{\text { Estados Unidos. As casas de detenção das cidades e dos }}$ condados (jails) abrigam pessoas detidas pela polícia, que aguardam jugamento e condenadas a penas de detenção inferiores a um ano. As prisões dos cinqüenta estados da União (state prisons) encerram os condenados a penas superiores a um ano, enquanto são enviados para as penitenciárias federais (federal prisons) os condenados pelo código penal federal, qualquer que seja a duração da pena. Cada setor possui seu próprio sistema de contagem, que não é rigorosamente idêntico ao longo do tempo, o que explica as inconsistências e as diferenças nos dados (inclusive quando provêm da mesma fonte).
Isso é apenas a ponta do iceberg penal americano, pois esses números não incluem os criminosos e delinqüentes em liberdade vigiada (probation) e sob liberdade condicional (parole) após terem purgado uma parte de sua pena ${ }^{4}$. Ora,

4 Esses números tornam-se mais ilustrativos quando se sabe que eles não incluem os detentos de menos de 18 anos presos nos centros para jovens delinqüentes. Estes últimos eram cerca de 100000 no início dos anos 90, ou seja, duas vezes a população carcerária francesa. 
o número destes excede de longe aquele dos detentos e ele também aumentou muito depois da reviravolta carcerária dos anos setenta. Entre 1985 e 1995, os efetivos dos condenados on probation saltaram de 2 para 3 milhões, enquanto seus homó- logos on parole passaram de 300000 para mais de 700 000. A população submetida à tutela penal atingiu, portanto, os 5,4 milhões no fim do período, contra 3 milhões dez anos antes e menos de um milhão em 1975. Tudo indica que ela ultrapassará os sete milhões antes do ano 2000.

Tabela 3 - Populações sob tutela penal nos Estados Unidos em 1995

\begin{tabular}{lcccc}
\hline & total & homens & brancos & negros \\
\hline Liberdade vigiada & 3096500 & 24545000 & 2057600 & 999220 \\
Prisões municipais & 499300 & 448000 & 262200 & 228500 \\
Penitenciárias federais e estaduais & 1078500 & 1014500 & 522100 & 538500 \\
Liberdade condicional & 700200 & 629900 & 368300 & 324700 \\
Total sob tutela penal & 5374500 & 4546400 & 3212200 & 2090900 \\
População adulta dos EUA & 194294000 & 93341200 & 163828200 & 22472100 \\
\% sob tutela penal & 2,77 & 4,87 & 1,96 & 9,31 \\
\hline
\end{tabular}

Fonte: BUREAU OF JUSTICE STATISTICS, Correctional Population in United States, 1995. Washington : U. S. Government Printing Office, 1996.

Estes 5,4 milhões de indivíduos representam $2,8 \%$ da população adulta do país e perto de um americano do sexo masculino sobre vinte. Entretanto, um homem negro em cada dez está hoje sob jurisdição criminal (cf. Tabela 3). Veremos, de fato, que a sobre-representação maciça e crescente dos afro-americanos em todos os níveis do sistema penal traduz o novo papel que este último assume no arsenal dos instrumentos de dominação racial desde as grandes revoltas dos guetos urbanos dos anos sessenta.

\section{A INDÚSTRIA DO ENCARCERAMENTO}

Outro indicador do boom que conhece a economia penal nos Estados Unidos: o item "encarceramento" no orçamento do Ministério da Justiça passou de 9 bilhões de dólares em 1982 a 32 bilhões em 1992. Ele sozinho consome atualmente um terço dos recursos públicos alocados na luta contra o crime, ou seja, 94 bilhões de dólares naquele ano, dos quais 41 bilhões para a polícia e 21 bilhões para os tribunais.

Pela primeira vez na história americana os governos locais dispendem mais a título de criminal justice que no capítulo educação (da qual eles são contudo responsáveis pelo nível primário e secundário), desde 1977 no caso das cidades e desde 1982 no dos condados (CHAMBLISS, 1991). Esta diferença vai se agravando: em 1995 os estados previam um crescimento de suas despesas de encarceramento em $8 \%$ ao ano em média, contra
$4,3 \%$ de aumento no ensino e $2,1 \%$ no principal programa de assistência às famílias carentes, Aid to Families with Depent Children (DIMASCIO, 1995). Enquanto o número de funcionários diminui nos serviços sociais e na educação, o pessoal que trabalha nas prisões estaduais dobrou durante a década passada, para atingir 347000 empregados, dentre os quais 221000 carcereiros.

"O Estado reconhece que não pode permitir que o crescimento dos orçamentos das prisões continue neste ritmo. O setor privado é o melhor meio de limitar este crescimento. Nós economizamos o dinheiro inicial e em seguida limitamos ao máximo os aumentos". Como indica esta tirada do presidente da Corrections Corporation of America (1996, p. 5), em seu último relatório anual aos acionistas, a corrida desvairada ao encarceramento na qual os Estados Unidos se lançou, fez nascer uma nova indústria, o encarceramento privado, cujas taxas de crescimento e de lucro rivalizam com aquelas dos setores de ponta da economia nacional ${ }^{5}$. Pois os estados, os condados e as cidades são incapazes de conter a onda de pri-

5 Corrections Corporation of A merica é a líder desta nova indústria com perto da metade das celas privadas do país. Fundada em 1983, a empresa de Nashville é responsável por 59 prisões em 19 estados e no estrangeiro (Porto Rico, Austrália e Inglaterra) para um cifra de negócios de 300 milhões de dólares, e que cresce $40 \%$ ao ano. 
sioneiros por eles mesmos detonada. Eles se voltam portanto para empresas especializadas, que prometem comprimir os custos de detenção de 10 a 20 por cento por cabeça, graças à sua maior eficiência, devida essencialmente aos baixos salários de seus carcereiros (que, contrariamente a seus colegas do setor público, geralmente não são sindicalizados).

Além do fornecimento de bens e serviços indispensáveis ao funcionamento de uma prisão (mobiliário, alimentação, entretenimento, cuidados médicos, telefonia etc.), desde muito tempo franqueado ao setor privado, cerca de vinte empresas partilham o mercado de construção e de administração de estabelecimentos privados de detenção. Estes últimos constituem ainda apenas uma pequena centena, repartidos em dezenove estados, mas se multiplicam a uma velocidade vertiginosa. De zero em 1983, o número de "leitos privados" passou a 15000 em 1990, antes de ultrapassar os 70000 em 1995, ou seja, cerca de 5\% da população aprisionada. E os dirigentes das principais empresas de encarceramento são unânimes em predizer que sua parte no mercado vai quadruplicar, na melhor hipótese, daqui até o ano 2000: “A era do preconceito contra as prisões privadas foi ultrapassada. Mais e mais estados consideram sem parti-pris a privatização. As prisões privadas já existem há algum tempo e passaram nos testes. Economizam o dinheiro do estado, cuidam bem dos prisioneiros. E isso atinge os jovens delinquientes: mais e mais condados pretendem privatizar seus estabelecimentos para jovens detentos"6.

Com 26 prisões federais e 96 penitenciárias estaduais que começaram a ser construídas em 1996, o financiamento da construção de estabelecimentos de detenção tornou-se um dos setores mais suculentos do mercado de debêntures. As grandes corretoras de Wall Street, tais como Goldman Sachs, Smith Barney Shearson e Merril Lynch, que não se enganam nisso, investem nele entre dois e três bilhões de dólares a cada ano.

6 Entrevistas realizadas pelo autor por ocasião do 1270 Congress of Corrections, encontro anual de profissionais de encarceramento, mantido sob a égide da A merican Corrections A ssociation (organismo fundado em 1870 e com mais de 24 000 membros), em Orlando, Flórida, em agosto último (e cuja análise aparecerá em um artigo ulterior). N. da T. 0 presente artigo foi escrito em novembro de 1997.
A implantação de penitenciárias afirmou-se, da mesma maneira, como um potente instrumento de organização do território. As vilas das zonas rurais decadentes, em especial, não economizam nenhum esforço para atraí-las: "Está longe a época em que a perspectiva de acolher uma prisão lhes inspirava esse grito de protesto: 'Not in my backyard'. As prisões não utilizam produtos químicos, não fazem barulho, não dispersam poluentes na atmosfera e não demitem seus empregados durante as recessões" (LOTKE, 1996, p. 18$)^{7}$. Bem ao contrário, elas trazem consigo empregos estáveis, comércios perenes e entradas fiscais regulares. O encarceramento é uma indústria próspera com um futuro radioso, e junto com ela uma promessa a todos aqueles que estão ligados à hiperinflação carcerária americana.

\section{A NOVA POLÍTICA PENAL AMERICANA}

Como se explica esse brutal fortalecimento do aparelho carcerário americano quando todos os observadores concordavam em predizer seu enfraquecimento há apenas vinte anos? A doutrina oficial na matéria é que ela responde ao crescimento irresistível da criminalidade e, notadamente, das violências contra pessoas. Após a "Guerra à pobreza" abortada nos sessenta, o governo americano decidiu conduzir uma "Guerra contra o crime" e emprega nisso os meios (ANDREAS, 1997), apoiado por uma opinião pública mais e mais inquieta em matéria de segurança.

Mas, de fato, esse argumento de senso comum é desmentido por todos os dados disponíveis. De um lado, a delinquiência e a criminalidade não aumentaram mas estagnaram, senão recuaram durante as duas décadas passadas. De outro lado, a maioria dos novos detentos que vêm se amontoar atrás das grades não são criminosos perigosos e inveterados, mas pequenos delinqüentes não violentos. Enfim, apesar da mídia, que faz do espetáculo cotidiano da violência criminal

\footnotetext{
7 A expressão "not in my backyard" (literalmente, "não no meu jardim") e sua sigla, NIMBY, fazem referência aos movimentos locais de luta contra os dejetos industriais e comerciais que surgiram nos anos 70 no movimento ecologista. Eles designam, por extensão, a oposição à implantação de toda instituicão que atente contra a "qualidade de vida" (e o preço imobiliário) de um lugar; usina, garagem de ônibus e depósito de descarga, mas também asilo, casa de acolhimento para os sem-teto, centros de desintoxicação etc.
} 
seu prato principal, a maior parte dos americanos não tem nenhum motivo para viver no terror da agressão.

Figura 1 - Evolução dos crimes e delitos nos Estados Unidos, 1973-1992

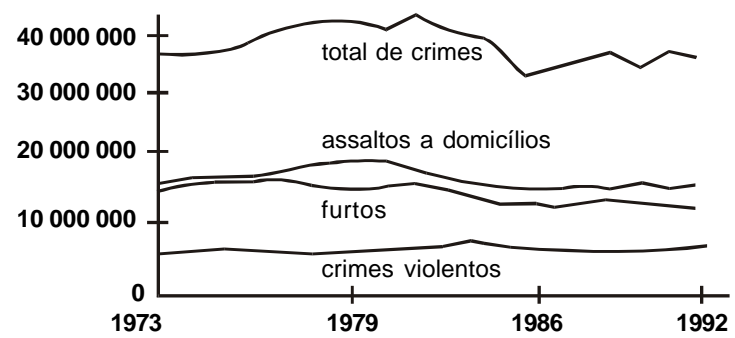

Fonte: BUREAU OF JUSTICE STATISTICS, Criminal Victimization in the United States, 1973-1992. Washington : U. S. Government Printing Office, 1994

Como mostra a Figura 1, o volume bruto dos crimes e delitos permaneceu estacionado e posteriormente decresceu durante o período correspondente à ascensão da população carcerária. De 1973 a 1982, cerca de quarenta milhões de americanos, considerando a média de bons e maus anos, foram vítimas de incidentes criminais. Em 1992, esse número caiu para cerca de 35 milhões e esta queda confirmou-se depois. Um exame aprofundado dos dados da National Crime Victimization Survey confirma a baixa das principais infrações à lei e refuta portanto a idéia de que a explosão do encarceramento traduziria aquela da criminalidade 8 .

Assim, no que diz respeito a violências contra pessoas, a freqüência dos assaltos qualificados (robbery) diminuiu entre 1974 e 1978, antes de aumentar até 1981; depois ela novamente decresceu, de 1981 a 1985, antes de crescer lentamente até 1994; isto sem jamais sair de uma banda estreita compreendida entre 200 e 250 incidentes por 100000 habitantes. A taxa de ataques violentos (aggravated assault) refluiu nitidamente de 1974 até meados dos anos 80, antes de estabilizar-se e depois aumentar de 1990 a 1993; depois ela caiu muito para atingir seu ponto mais baixo em 23 anos. Estacionária de 1977 a 1979, a probabilidade de ser vítima de golpes e ferimentos

\footnotetext{
8 A N ational Crime V ictimization Survey é uma enquete anual realizada pelo D epartamento de Recenseamento junto a uma amostra representativa de domicílios, que permite seguir a evolução de sete categorias de crimes e delitos. Ela é considerada a fonte de informação mais confiável sobre a criminalidade nos Estados Unidos.
}

(simple assault) declinou, em seguida, interruptamente; está hoje no mesmo nível do final dos anos 60.

A taxa de homicídios voluntários flutuou entre 8 e 10 por 100000 habitantes durante o último quartel de século sem marcar uma tendência particular. O número de mortes recenseadas pelo FBI

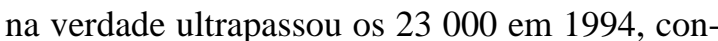
tra 20700 vinte anos antes, mas, referido à população do país, sua incidência é rigorosamente a mesma. Quanto aos crimes e delitos que envolvem os bens (roubo, furto simples e furto de veículo), sua frequiência baixou de maneira uniforme e contínua de 1974 a 1994 (BUREAU OF JUSTICE STATISTICS, 1997).

Se o número de detentos americanos quadruplicou após meados dos anos 70 enquanto a criminalidade quase não aumentou, é que o recurso ao encarceramento alargou-se e banalizou-se. Ao longo dos anos, a detenção foi aplicada com uma freqüência e uma severidade crescentes ao conjunto de delinqüentes, pequenos ou grandes, e de criminosos, perigosos ou não. Como o prova o fato de que a proporção de autores de crimes violentos entre as pessoas que vão para trás das grades das prisões estaduais caiu de $50 \%$ em 1980 a menos de $27 \%$ em 1992, enquanto a parte dos condenados por comércio ou consumo de drogas saltou de 7\% para 29\%. Nesse ano, o condenado típico enviado para detenção era um homem de menos de trinta anos (53\% dos ingressantes), de origem afro-americana (54\%), não tendo terminado seus estudos secundários (dois terços), posto na cela por um delito ou crime não-violento em mais de sete casos sobre dez. Entre os $27 \%$ de novos admitidos em detenção que cometeram um crime violento, $11 \%$ foram condenados por roubo qualificado e $7 \%$ por golpes e ferimentos, contra $5 \%$ por violências sexuais e $3,5 \%$ por assassinato (IRWIN \& AUSTIN, 1995, p. 23).

Essas tendências são particularmente pronunciadas nos estados campeões de encarceramento. De 100 pessoas condenadas à prisão no Texas no começo da presente década, 77 o foram por somente quatro categorias de crimes e delitos relativamente menores: posse e transporte de drogas ( $22 \%$ e $15 \%$ respectivamente), roubo e furto $(20 \%$ cada um). Por outro lado, mais da metade dos condenados de acordo com a legislação sobre entorpecentes o foram por posse de menos de um grama de droga (FABELO, 1993). A Califórnia multiplicou sua população carcerária por quatro 
entre 1980 e 1993; 76\% desse crescimento se explica pela reclusão de criminosos não violentos. Essa desproporção é ainda mais marcada nas penitenciárias federais, uma vez que $94 \%$ dos 40 000 novos detentos que são admitidos ali no curso de um ano o são por crimes não violentos (DONZIGER, 1996, p. 17-19).

Em suma, as prisões americanas transbordam de condenados que não seriam jogados atrás das grades há vinte anos e que de modo verossímil aí não apodreceriam se o país estivesse mais bem informado da realidade de sua política penal ${ }^{9}$. O que mudou nesse meio tempo não foi a freqüência e o caráter da atividade criminal, mas a atitude das autoridades face à delinqüência e à sua principal fonte, a miséria urbana concentrada das metrópoles.

\section{AS CAUSAS DA POLÍTICA DE ENCARCE- RAMENTO}

Três séries causais se interpenetraram para fazer do encarceramento a punição escolhida pelos Estados Unidos e produzir a hiperinflação carcerária inédita que conheceu o país, da presidência de Nixon a nossos dias. A primeira compreende um rosário de mudanças internas no sistema judiciário ligadas ao declínio do "ideal da reabilitação" (ALLEN, 1981) e ao endurecimento correlato do modo de fixação das penas.

Hegemônica nos Estados Unidos desde o entre-guerras, a idéia de que o encarceramento visa reformar o criminoso com o objetivo de, por fim, reinseri-lo na sociedade, foi bruscamente refutada pela convergência inesperada de críticas de direita e de esquerda (MCKELVEY, 1977). Os conservadores sempre sustentaram que a missão prioritária da prisão é punir e não reabilitar: sendo uma sociedade composta de duas espécies distintas de indivíduos, os cidadãos honestos (the innocent) e a gente má (the wicked), o encarceramento

9 Irwin \& Austin apresentam uma análise qualitativa bastante aguda da carreira social e criminal de uma amostra aleatória de 154 prisioneiros em três estados (Washington, Nevada e Illinois). De onde sobressai que "mais da metade das pessoas enviadas para prisão cometeu delitos e crimes que não têm nenhuma das características que apresentam 0 que a opinião [pública] considera como um crime grave" (1997, p. 32-57). A maioria dos detentos são delinqüentes de ocasião (por oposição aos "criminosos por profissão"), que não seriam encarcerados se as pessoas conhecessem seu perfil e as circunstâncias que os conduziram a infringir a lei. deve servir antes de tudo para proteger os primeiros dos segundos, prendendo estes últimos entre quatro paredes o maior tempo possível (WILSON, 1975). A novidade, que surgiu na década de sessenta, foi que essa visão retrógrada de prisão encontrou um reforço poderoso na crítica progressista, para a qual a reabilitação é apenas uma fachada e a dosagem das penas um exercício de poder puramente arbitrário.

Os defensores do "desencarceramento" argumentavam então que as medidas de educação e de apoio à reinserção não têm nenhum efeito, senão o de legitimar uma instituição total que, por definição, destrói aqueles que lhe são confiados. Além disso, eles atacam resolutamente a modulação das penas segundo as características individuais dos crimes e de seus autores, permitida pelo regime chamado "penas indeterminadas", pois este desfavoreceria gravemente os condenados oriundos de regiões mais baixas do espaço social (isto é, pobres e negros) ${ }^{10}$. O remédio preconizado: fixar as penas a priori em uma banda estreita, limitar a autoridade discricionária dos juízes, denunciar sem descanso a hipocrisia do paradigma "correcional".

Os reformadores dos anos setenta tinham consciência de que suas demandas corriam o risco de dar credibilidade a proposições diametralmente opostas dos partidários de uma extensão do aparelho carcerário. Mas uma reforma, não importa qual, parecia-lhes preferível a um status quo penal julgado intolerável pela medida do ethos libertário dos sixties ${ }^{11}$. E esperavam que os políticos recuassem diante do custo exorbitante do aprisionamento, para se voltar para penas alternativas. É pouco dizer que suas expectativas foram

10 Sob o regime de indeterminate sentencing, introduzido nos anos 20, o tribunal condena um criminoso a uma pena de detenção definida por uma banda larga (por exemplo, entre dois e oito anos). A duração da pena efetivamente cumprida é fixada em seguida por um comitê de aplicação de penas (parole board) em função do comportamento do prisioneiro e de seu encaminhamento para a "reabilitação".

11 Há aqui um paralelo flagrante com a recente "reforma" dos auxílios sociais votada pelo Congresso americano em 1996 - com 0 assentimento do presidente Clinton - , "reforma" que vem para abolir o direito à assistência das famílias monoparentais carentes, para fazer do trabalho assalariado desqualificado uma obrigação cívica (WACQUANT, 1997a). Pois, também neste caso, são os reformadores ditos liberais (ou seja, à esquerda no tabuleiro político americano) que tornaram possível a aprovação desta lei retrógrada, 
cruelmente frustradas. O historiador David Rothman (1995, p. 34), que participou ativamente dessa campanha para denegrir o modelo da reabilitação, apresenta seu balanço desolador nestes termos: "Os reformadores se enganaram em tudo. O regime das penas fixas foi adotado no anos $80 \mathrm{em}$ nível federal e em torno de um terço dos estados. Mas, à exceção de algumas raras jurisdições (sobretudo no Minnesota), as novas diretivas penais aumentaram as durações de detenção; elas tiveram impacto pequeno sobre as disparidades (sociais e raciais): favoreceram a superlotação das prisões e reduziram o papel dos juízes na fase de determinação das penas, aumentando o poder discricionário dos promotores. A rejeição do modelo da reabilitação contribuiu igualmente para transformar as prisões em entrepostos: se os programas de formação e de educação são perniciosos e fúteis, por que o Estado desperdiçaria seu dinheiro para financiá-los?"

O segundo motor da inflação carcerária americana é a mutação dos usos político-midiáticos da criminalidade como reação aos movimentos de contestação dos anos 60. Para sufocar os tumultos populares provocados pela guerra do Vietnã e pela mobilização dos negros em favor da igualdade civil, os políticos conservadores, republicanos e democratas vão aperceber-se do "problema", e fazer da "luta contra o crime" seu principal contra-ataque à expansão (modesta) do Estado social, necessária para suprimir a pobreza e a desigualdade racial (BUTTON, 1978, p. 163166). Introduzido por Nixon durante a campanha presidencial de 1968, o tema securitário da law and order vai fornecer um leitmotiv eleitoral tanto mais apreciado porque permite exprimir em um idioma de aparência cívica — garantir a segurança e a tranqüilidade dos cidadãos — a rejeição às reivindicações negras e, por conseguinte, exorcizar o espectro ameaçador da "integração".

O sucesso desse pânico moral em torno da criminalidade provém da cumplicidade estrutural,

adotando alguns temas caros aos conservadores (notadamente a idéia de que o Estado do Bem-Estar Social é disfuncional) e sancionando medidas coercitivas e paternalistas (tais como a obrigação de emprego no fim de dois anos e a limitação por vida da duração do auxílio), sob pretexto de que seus efeitos nefastos seriam compensados pela adoção de outras medidas progressistas (tais como a criação de empregos públicos), as quais se podia facilmente prever que não veriam a luz do dia. $\mathrm{E}$ que qualquer reforma vale mais que nenhuma reforma, pois o sistema existente deserda os despossuídos. que se estabelece ao longo dos anos, sobre esse terreno entre o campo político, o campo jornalístico e o campo das instituições penais. Na origem, combater o crime é o grito de convergência de políticos preocupados em tranquiilizar as classes médias brancas das zonas suburbanas assustadas pela insegurança das cidades (das quais fugiram aos milhões), quanto opostas aos políticos do welfare (assistência social) e da affirmative action (promoção preferencial das minorias), que elas consideram como favores indevidos concedidos aos negros responsáveis pelas revoltas urbanas. Mas, sob a pressão da mídia, a necessidade de ser tough on crime vai rapidamente se impor tanto ao conjunto dos políticos como aos promotores e juízes, cujos postos são eletivos e para quem a suspeita de laxismo equivale a uma sentença de morte profissional (ANDERSON, 1995) ${ }^{12}$.

Nesse meio tempo o crime tornou-se também o assunto predileto dos jornalistas. De fato, ele permite à mídia fazer espetáculo barato e portanto conservar ou conquistar partes do mercado, satisfazendo a fascinação mórbida do público pela violência. É assim que a criminalidade invade as primeiras páginas dos jornais e as telas de televisão até o ponto de saturação, mesmo quando sua incidência baixa no país (LICHTER \& LICHTER, 1994). Não nos surpreenderemos em perceber que a obsessão comum da mídia e dos políticos pelo crime casa-se com o fervor dos responsáveis pelas instituições penais do país. Ministério da Justiça, administrações penitenciárias dos estados, departamentos de polícia, sindicatos de agentes penitenciários e lobbies industriais ligados ao complexo carcerário: todos concordam em ver no crime control uma prioridade nacional que não poderia absolutamente ser freada ${ }^{13}$. É sobretudo uma pri-

12 Chambliss (1994, especialmente p. 187-192) oferece uma análise sucinta e precisa da fabricação deste pânico moral que permite ver, sobretudo, como as pesquisas de opinião (sobre "o principal desafio perante o qual o país está defrontado") constituíram em problema nacional uma questão com a qual a "opinião" quase não se preocupava até que os políticos, a mídia e os pesquisadores a impusessem.

13 O departamento de pesquisa do Ministério Federal da Justiça chega a produzir estudos estatísticos fraudulentos visando provar que o custo astronômico do encarceramento é de longe inferior ao custo presumido dos crimes que os prisioneiros teriam cometido se tivessem sido deixados em liberdade. Zimring \& Hawkins (1988) oferecem uma crítica devastadora desta "nova aritmética do aprisionamento" reveladora das derrapagens intelectuais que provoca $0 \mathrm{em}$ baraço oficial pelo "todo carcerário". 
oridade bem feita para justificar o crescimento sem fim de seus efetivos, de seus orçamentos e de suas prerrogativas.

O resultado desse conluio político-midiáticopenal é a multiplicação das leis repressivas - a Califórnia votou mais de mil em quinze anos que estendem o recurso ao aprisionamento, alongam a duração das penas de detenção (sob a aparência de restabelecer a "verdade das penas"), estipulam penas mínimas incomprimíveis para um largo leque de infrações e chegam mesmo a impor a prisão perpétua no terceiro crime ou delito grave (disposição vendida ao eleitorado graças à expressão do beisebol, "Three Strikes and You're Out").

\section{CONCLUSÃO}

Duas tendências importantes chamam a atenção de todos os observadores da cena penal americana contemporânea. De um lado, a porcentagem dos detentos encarcerados por infração à legislação sobre entorpecentes elevou-se de 5\% em 1960 a 9\% em 1980, para alcançar o terço em 1995. Ao mesmo tempo, a parte dos afro-americanos entre os novos admitidos nas prisões federais e estaduais quase dobrou, de maneira que, pela primeira vez no século, os prisioneiros de cor ali são majoritários (55\%), enquanto os homens negros somam apenas 7\% na população do país. $\mathrm{O}$ cruzamento dessas tendências aponta para a terceira causa da quadruplicação em vinte anos dos efetivos aprisionados nos Estados Unidos: $o$ sistema penal em parte substituiu e em parte juntou-se ao gueto como mecanismo de controle racial, depois que este último revelou-se inapto para conter o proletariado negro urbano no lugar que lhe cabe no novo espaço social norte-americano (WACQUANT, 1997b).

É verdade que os negros sempre estiveram sobre-representados no seio das penitenciárias, e isso por duas razões. A primeira é que eles cometem proporcionalmente mais crimes que os bran$\cos$, em função da diferença de estatuto sócioeconômico entre as duas comunidades (um afroamericano entre três vive abaixo da linha oficial de pobreza contra um euro-americano entre dez) e da segregação extrema que lhes é infringida nas cidades ${ }^{14}$. A segunda é a discriminação que asso-

14 D ouglas Massey (1995) mostra como a "hipersegregação" dos negros se combina com sua alta taxa de pobreza para la todos os patamares do sistema judiciário (CRUTCHFIELD et al., 1994; DONZIGER, 1996 p. 99-129): por "crime igual” os negros são freqüentemente mais detidos, mais vezes denunciados diante dos tribunais e mais pesadamente condenados que os brancos. Mas o agravamento espetacular da "desproporção racial" no período recente sugere que uma nova relação se estabelece entre o encarceramento e a divisão de casta que sustenta a estrutura da sociedade americana.

O fosso entre negros e brancos aprofundouse muito no curso da década passada, ao ponto que em 1993 a taxa de encarceramento dos afroamericanos fosse mais de dez vezes superior àquela de seus compatriotas de origem européia (1947 contra 306 por 100000 ). Mas, sobretudo, o "escurecimento" sofrido pela população carcerária explica-se quase que inteiramente pela política de "guerra às drogas" lançada com estardalhaço por Ronald Reagan e ampliada depois por seus sucessores (TONRY, 1995). Essa política serviu de cobertura a uma verdadeira guerrilha policial e judiciária contra os traficantes de rua e, por extensão, contra os habitantes dos bairros negros deserdados. Esses últimos são, de fato, suspeitos de desviarem-se das normas culturais nacionais e de adotarem "comportamentos anti-sociais", que o discurso pseudocientífico sobre a underclass sustenta ser a causa das desagregações sociais na metrópole (cf., por exemplo, MINCY, 1994). Sua submissão à tutela punitiva do aparelho carcerário estende e intensifica simultameamente a tutela paternalista que os serviços sociais já fazem pesar sobre eles. De outro lado, ela permite explorar e nutrir - a hostilidade racial latente do eleitorado e seu desprezo pelos pobres, com um rendimento midiático e político máximo (CHAMBLISS, 1994).

Longe de perseguir o flagelo em todo lugar onde ocorre, a começar pelos bairros brancos prósperos e os campi universitários, a campanha estatal contra as drogas concentra-se no gueto. Como resultado, a taxa de detenção de negros de acordo com a legislação sobre entorpecentes decuplicou em dez anos para chegar ao pico de 1800 por 100000 em 1989, enquanto esta mes-

criar um "nicho ecológico" único, excepcionalmente propício ao desenvolvimento da violência e da criminalidade. 0 que explica que os negros urbanos sejam os primeiros autores, mas também as principais vítimas da criminalidade violenta. 
ma taxa flutuava, entre os brancos, entre 220 e 250 por 100000 (ainda que o consumo de droga seja o mesmo nas duas comunidades). E o número de negros presos nas redes do aparelho penal explodiu, com todas as consequiências deletérias que conhecemos sobre sua inserção salarial e sua vida familiar: é o caso hoje da metade dos jovens afro-americanos das grandes cidades, se juntarmos aos prisioneiros os efetivos colocados em liberdade vigiada e condicional. Conseqüentemente, uma profunda simbiose estrutural e funcional se estabeleceu entre o gueto e a prisão. As duas instituições se interpenetram e se completam na medida em que ambas servem para garantir o confinamento de uma população estigmatizada por sua origem étnica e tida como supérflua tanto no plano econômico como no plano político ${ }^{15}$.

$\mathrm{Na}$ conclusão de um exame cerrado das relações entre raça, crime e punição nos Estados Unidos, o jurista Michael Tonry afirma que os formuladores da guerra às drogas agiram com pleno conhecimento de causa: "[Eles] sabiam que o uso de drogas declinava junto à grande maioria da população. Sabiam que seu uso não declinava nas camadas desfavorecidas do sub-proletariado urbano. Sabiam que a guerra às drogas seria conduzida principalmente nos bairros segregados das grandes cidades e que aqueles que seriam detidos e presos seriam principalmente jovens negros e latinos" (1995, p. 104).

Forçosamente, é preciso portanto concluir que a "guerra às drogas" traduz bem a vontade de

15 Esta simbiose encontra uma expressão relevante nos textos e no modo de vida apresentados pelos músicos de rap (como o testemunha o destino trágico do cantor-compositor Tupac Shakur). penalizar a pobreza e conter o cortejo das "patologias" que lhe são associadas, seja no seio do gueto, seja, quando elas transbordam seu perímetro, nas prisões que lhe são de agora em diante simbioticamente reunidas. Além disso, o acoplamento funcional entre o aparelho penal e o gueto negro inscreve-se na prática de uma "nova penalogia", cujo objetivo não é mais o de prevenir o crime, nem de reinserir os delinqüentes na sociedade, uma vez purgada a pena, mas isolar os grupos percebidos como perigosos e neutralizar seus membros mais rebeldes (disruptifs) por uma gestão aleatória dos riscos (SIMON \& FEELEY, 1995).

Todas as pesquisas históricas e comparativas concorrem para demonstrar que o nível de encarceramento de uma sociedade não tem relação com sua taxa de criminalidade: ela revela fundamentalmente escolhas culturais e políticas (CHRISTIE, 1997). A esse título, a hiperinflação carcerária que os Estados Unidos conheceram de Nixon a Clinton é reveladora - constituiu a face escondida do "modelo social" americano. O sobredesenvolvimento do setor penal é, de fato, a contrapartida necessária do enfraquecimento do Estado do Bem-Estar Social neste período, e a associação do gueto e da penitenciária é o complemento lógico da política de criminalização da miséria perseguida pelas autoridades do país (WACQUANT, 1996). Não mais que em outras sociedades, os discursos que ligam crime e punição nos Estados Unidos não têm outro valor que o ideológico. Mesmo que estejam longe de se dar conta disto, participam da construção social de um Estado penal que constitui, incontestavelmente, uma das experiências históricas mais imprevistas e mais cruéis da era democrática.

Recebido para publicação em abril de 1999.

Loïc Wacquant (loic@uclink4.berkeley.edu) é Professor do Departamento de Sociologia da University of California-Berkeley e pesquisador do Centro de Sociologia Européia do Collège de France.

\section{REFERÊNCIAS BIBLIOGRÁFICAS}

\begin{abstract}
ALLEN, F. 1981. The Decline of the Rehabilitative Idea : Penal Policy and Social Purpose. New Haven : Yale University Press.
\end{abstract}

ANDERSON, D. C. 1995. Crime and the Politics of Hysteria: How the Willie Horton Story
Changed American Justice. New York : Times Books.

ANDREAS, P. 1997. The Rise of the American Crimefare State. World Policy Journal, vol. 14, n. 3, p. 37-45, Fall. 
BLUMSTEIN, A. \& COHEN, J. 1973. A Theory of the Stability of Punishment. Journal of Criminal Law and Crimonology, vol. 64, p. 198207.

BLUMSTEIN, A., COHEN, J. \& NAGIN, D. 1976. They Dynamics of a Homeostatis Punishment Process. Journal of Criminal Law and Crimonology, vol. 67, p. 317-334.

BUREAU OF JUSTICE STATISTICS. 1994. Criminal Victimization in the United States, 1973-1992. Washington : U. S. Government Printing Office.

1994. Prisioners in 1993. Washington : U. S. Government Printing Office.

. 1995. Jail and Jail Inmates, 1993-1994. Washington : U. S. Government Printing Office.

1996. Correctional Population in United States, 1995. Washington : U. S. Government Printing Office.

1996. Prison and Jail Inmates, 1995. Bureau of Justice Bulletin, Washington, oct.

. 1997. Prisioners in 1996. Washington : U. S. Government Printing Office.

1997. Correctional Populations in the United States, 1995. Washington : U. S. Government Printing Office.

BUTTON, J. 1978. Black Violence : Political Impact of the 1960s Riot. Princeton : Princeton University Press.

CHAMBLISS, W. J. 1991. Trading Textbooks for Prison Cells. Alexandria, Virginia : National Center on Institutions and Alternatives.

1994. Policing the Ghetto Underclass : The Politics of Law and Law Enforcement. Social Problems, vol. 41, n. 2, p. 177-194, May.

CHRISTIE, N. 1997. An Essay in Penal Geography. Manuscrit. Oslo : Departament of Criminology, University of Oslo.

COHEN, S. 1979. The Punitive City : Notes on the Dispersal of Social Control. Contemporary Crises, vol. 3, p. 339-363.

CRUTFIELD， R., BRIDGES，G. S. \& PITCHFORD, S. 1994. Analytical and Aggregation Biases in Analyses of
Imprisonment : Reconciling Discrepancies in Studies of Racial Disparity. Journal of Research in Crime and Delinquency, vol. 31, n. 2, p. 166-182, May.

DEPARTMENT OF JUSTICE. 1997. National Crime Victimization Survey : Criminal Victimization, 1973-1995. Washington : Government Printing Office.

DIMASCIO, W. 1995. Seeking Justice : Crime and Punishment in America. New York : Edna McConnell Clark Foundation.

DONZIGER, S. R. (ed.). 1996. The Real War on Crime : The Report of the National Criminal Justice Commission. New York : Basic Books.

FABELLO, T. 1993. Sentencing Dynamics Study. Austin : Criminal Justice Policy Council.

FOUCAULT, M. 1975. Surveiller et punir. Naissance de la prison. Paris : Gallimard.

IGNATIEFF, M. 1978. A Just Measure of Pain : The Penitenciary in the Industrial Revolution, 1750-1850. London : Macmillan.

IRWIN, J. \& AUSTIN, J. 1997. It's about Time : America's Imprisonment Binge. Belmont : Wadsworth.

LICHTER, R. \& LICHTER, L. 1994. Media Monitor 1993 : The Year in Review. Washington : Center for Media and Public Affairs.

LOTKE, E. 1996. The Prison-Industrial Complex. Multinational Monitor, vol. 17, p. 18-22.

MASSEY, D. 1995. Getting Away with Murder : Segregation and Violent Crime in Urban America. University of Pennsylvania Law Review, vol. 143, n. 5, p. 1203-1232, May.

MCKELVEY, B. 1977. American Prisons : A History of Good Intentions. Montclair, New Jersey : Patterson-Smith.

MINCY, R. 1994. The Underclass : Concept, Controversy, and Evidence. In : DANZIGER, S. et al. Confronting Poverty : Prescriptions for Change. Cambridge : Harvard University Press.

NATIONAL ADVISORY COMMISSION ON CRIMINAL JUSTICE STANDARDS AND GOALS. 1973. Task Force Report on Corrections. Washington : Government Printing Office. 


\section{PRESIDENT'S COMMISSION ON LAW} ENFORCEMENT AND ADMINISTRATION OF JUSTICE. 1967. Task Force Report : Corrections. Washington : Government Printing Office.

ROTHMAN, D. 1971. The Discoverty of the Asylum : Social Order and Disorder in the New Republic. Boston : Little, Brown.

1995. American Criminal Justice Policies in the 1990s. In : BLOMBERG, T. G. \& COHEN, S. (ed.). Punishment and Social Control. New York : Aldine de Gruyter.

SCULL, A. T. 1977. Decarceration : Community Treatment and the Deviant, a Radical View. Englewood Cliffs : Prentice-Hall.

SIMON, J. \& FEELEY, M. M. 1995. True Crime : The New Penology and Public Discourse on Crime. In : BLOMBERG, T. G. \& COHEN, S. (ed.). Punishment and Social Control. New
York : Aldine de Gruyter.

WACQUANT, L. 1996. De l'Etat charitable à l'Etat pénal : notes sur le traitement politique de la misère en Amérique. Regards sociologiques, n. 11, p. $30-38$.

1997a. Les pauvres en pâture : la nouvelle politique de la misère en Amérique. Hérodote, n. 85, p. 21-33, printemps.

1997b. Elias in the Dark Ghetto. Amsterdam Sociologisch Tidjschrift, no prelo, dec.

WILSON, J. Q. 1975. Thinking about Crime. New York: Vintage.

ZIMRING, F. \& HAWKINS, G. 1988. The New Mathematics of Imprisonment. Crime and Delinquency, vol. 34, n. 3, p. 425-436, oct.

1991. The Scale of Imprisonment. Chicago : The University of Chicago Press. 